\title{
HIGH PREVALENCE OF HOUSEHOLD PESTICIDES AND THEIR UNSAFE USE IN RURAL SOUTH INDIA
}

\author{
GRACE A. CHITRA, PRABHDEEP KAUR, TARUN BHATNAGAR, \\ PONNAIAH MANICKAM, and MANOJ V. MURHEKAR
}

National Institute of Epidemiology, Ayapakkam, Chennai, Tamil Nadu, India

ICMR School of Public Health

\begin{abstract}
Objective: To estimate the prevalence of usage, unsafe practices and risk perception regarding household pesticides in a rural community of Tamil Nadu, India. Materials and Methods: In a cross-sectional survey we used a pre-tested questionnaire and trained interviewers to collect information on household pesticide use for the past 6 months from any adult member of randomly selected households. Results: Out of 143 households, $95 \%$ used at least one household pesticide (95\% CI: 93.5-99.5) and 94\% used at least one household pesticide specifically for mosquito control. The most commonly used pesticides were mosquito coils (75\%), mosquito liquid vaporizers (36\%), ant-killing powder (24\%) and moth/naphthalene balls $(18 \%)$. The major non-chemical methods of pest control were rat traps $(12 \%)$ and mosquito bed nets $(7.5 \%)$. Out of the mosquito coil users, $61 \%$ kept the windows and doors closed while the coil was burning. Out of the moth ball users, $88 \%$ left them in the place of use till they fully vaporized. Nearly half of the users did not know that household pesticides were harmful to their health and the health of their children. Conclusions: The use of household pesticides was highly prevalent in this rural community. The prevalence of unsafe practices while handling them was also high. We recommend that the users of household pesticides be educated about the health hazards and about safe practices and non-chemical methods of pest control be promoted.
\end{abstract}

Key words:

Household pesticides, Mosquito coil, Prevalence, Cross-sectional survey, Tamil nadu, India

\section{INTRODUCTION}

Pesticides, including insecticides, fungicides, rodenticides, and herbicides are used in households to control mosquitoes, ants, flies, cockroaches, mice, and termites [1,2]. Surveys from developed countries estimate the use of household pesticides and therefore provide key information about the potential for exposure [3]. In the United States of America, $82 \%$ of households and $80-85 \%$ of households in the United Kingdom used household pesticides [3,4]. Household pesticide exposure (including prenatal exposure) is related to various adverse health outcomes [1]. In fact, some of the studies from developed countries indicated that exposure to household pesticides could be a risk factor for different types of cancer [5-9]. In these studies, exposures varied from garden or lawn pesticides to naphthalene balls (commonly called moth balls). In contrast to this, in developing countries, exposure to mosquito coil smoke was studied and reported as a probable risk factor for asthma [10] and lung cancer [11]. In 2008, the Indian insecticide market was worth US $\$ 340 \mathrm{mln}$ and increased from US \$110 mln in 2001, with the estimated annual growth of $13 \%$ [12]. Research done in many parts of India suggests that mosquito

Received: April 25, 2012. Accepted: November 8, 2012.

Corresponding author: G.A. Chitra, ICMR School of Public Health, National Institute of Epidemiology, Ayapakkam, Chennai, Tamil Nadu, India, Pin: 600077 (e-mail: chitragrace@yahoo.co.uk). 
control products are the most commonly used household pesticides in India. Out of these, mosquito coils are the most commonly used household pesticide product [1317]. However, there is lack of information on other types of household pesticides such as naphthalene/moth balls, ant control powder and "poison chalk". Furthermore, exposure to household pesticides is dependent on the amount and place of use, usage practices, storage and disposal methods $[1,3]$. The user's risk perception related to pesticides also affects the usage pattern and subsequent exposure $[18,19]$.

We conducted a cross-sectional survey in a rural setting in Tamil Nadu, India to estimate the prevalence of the use of household pesticides and non-chemical methods of pest control. We also described the practices associated with the safe use of pesticides and the household pesticide-related health risk perceptions of the community.

\section{MATERIALS AND METHODS}

We conducted a population-based cross-sectional survey in the Nemam village, Thiruvallur district, in the state of Tamil Nadu, India (Census 2001 population: 99 916) [20]. We estimated a sample size of 154 households with $90 \%$ prevalence of the use of household pesticides (assessed through a pilot study), with 5\% absolute precision, $95 \%$ confidence interval (CI) and 10\% non-response. Households were selected through simple random sampling from a sampling frame of readily available listing of households with identifier information.

Household pesticides were defined as any pesticide that is sold to the user for the purpose of being applied only in the household environment and intended to destroy, deter, render harmless, prevent the action of or otherwise exert a controlling effect on any harmful pest by chemical or biological means, which is not used on fields or farms or for commercial storage applications [21]. We defined mosquito coils as any spiral made from a dried paste of pyrethrum powder and other substances, which when lit burns slowly to produce a mosquito-repellent smoke. Mosquito liquid vaporizer was defined as any device that generates mosquito repellent in the form of vapor. We defined ant repellents as household pesticides usually used to control ants in the form of dust or powder, like "Gamaaxine" (Lindane) and methyl parathion. In many countries, Lindane-based products have been banned due to their persistency, and methyl parathion-based biocides are banned due to their acute toxicity. Moth balls were defined as small pellets or balls of a pungent substance, typically naphthalene, put in storage areas and cupboards to repel insects. "Poison chalk" included insecticides (mainly Cypermethrin and Deltamethrin) in the form of normal looking chalks.

We interviewed any available adult member of the household with a structured, pre-coded questionnaire in the local language Tamil. We collected demographic characteristics, household pesticide use and behavior, nonchemical methods of pest control and health risk perception. We used pictures of the various types of household pesticides to assist in the recognition and aid in recall. The interviewers were trainees of public health training programs of the ICMR School of Public Health at the National Institute of Epidemiology (NIE). The training of interviewers and field supervision assured the quality of data collection.

We entered data using Epi Info 3.5.3 [22] and used SPSS 16.0 [23] for analysis. We calculated the prevalence of the households that: 1) used at least one household pesticide, 2) used at least one household pesticide for mosquito control, and those that 3 ) used at least one household pesticide for other pest control, along with its $95 \%$ CI. We categorized the respondents into three levels of educational status; "illiterate" (i.e. respondents with no formal schooling), "low educational status" (i.e. respondents with less than eight years of schooling) and "high educational status" (i.e. respondents with more 
than eight years of schooling and those who completed a higher level of education a high school diploma and those who completed a higher level of education).We also calculated the frequency of household pesticide usage related to unsafe behavior, non-chemical methods of pest control and health risk perception.

We collected a written informed consent from all the participants. The study was approved by the Institutional Ethics Committee of NIE (ICMR), Chennai, India.

\section{RESULTS}

We collected data from 143 households (92\% response rate). Among the respondents, 97 were women (67.8\%), 73 were homemakers (51\%), 33 were illiterate $(23 \%)$ and 56 $(39 \%)$ were of high educational status. The majority of the households (75\%; $\mathrm{N}=109)$ reported monthly family income equaling less than US $\$ 100$. Forty five percent $(\mathrm{N}=65)$ houses were of pucca type ${ }^{1}$ and $22 \%(\mathrm{~N}=32)$ were inhabited by children under the age of five years (Table 1 ).

Among the 143 households, at least one type of household pesticides was used in 138 households (96.5\%; 95\% CI: 93.5-99.5), at least one household pesticide for mosquito control was used in 135 households (94.4\%; 95\% CI: 90.6-98.2), and at least one household pesticide for controlling pests other than mosquitoes was used in 64 households (44.7\%; 95\% CI: 36.6-52.9). Seventy five percent $(\mathrm{N}=107)$ households used mosquito coils and $36 \%(\mathrm{~N}=51)$ used mosquito control liquidators for mosquito control. Ant repellents were used by $24 \%$ households $(\mathrm{N}=34)$. Mothballs were used in 25 households (18\%). The major non-chemical methods of pest control were rat traps and mosquito bed nets $(\mathrm{N}=17 ; 12 \%)$ and $(\mathrm{N}=7 ; 5 \%)$, respectively (Figure 1 ).

Mosquito control liquid vaporizers and mosquito coils were used every day in 39 of $51(76 \%)$ and 63 of 107

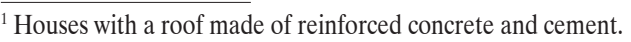

Table 1. General characteristics of the study participants, Nemam village, Tamil Nadu, India, 2010

\begin{tabular}{|c|c|c|}
\hline \multirow{2}{*}{ Parameters } & \multicolumn{2}{|c|}{ Respondents $(\mathrm{N}=143)$} \\
\hline & $\mathrm{n}$ & $\%$ \\
\hline \multicolumn{3}{|l|}{ Individual } \\
\hline female gender & 97 & 68 \\
\hline age $18-59$ years & 136 & 95 \\
\hline \multicolumn{3}{|l|}{ education } \\
\hline illiterate & 33 & 23 \\
\hline low educational status & 54 & 38 \\
\hline high educational status & 56 & 39 \\
\hline \multicolumn{3}{|l|}{ occupation } \\
\hline homemaker & 73 & 51 \\
\hline laborers & 25 & 18 \\
\hline employed & 37 & 26 \\
\hline unemployed & 8 & 6 \\
\hline \multicolumn{3}{|l|}{ Household } \\
\hline \multicolumn{3}{|l|}{ age category } \\
\hline adults only & 34 & 24 \\
\hline children aged 5-18 years & 77 & 54 \\
\hline children aged $<5$ years & 32 & 22 \\
\hline \multicolumn{3}{|l|}{ type of house } \\
\hline kutcha & 22 & 15 \\
\hline semi-pucca & 57 & 40 \\
\hline pucca & 64 & 45 \\
\hline $\begin{array}{l}\text { reported monthly household } \\
\text { income < US } \$ 100\end{array}$ & 109 & 76 \\
\hline
\end{tabular}

$(60 \%)$ households, respectively. They were mainly used in the sleeping area. The mean duration of mosquito coil use was $7.6(\mathrm{SD} \pm 2.2) \mathrm{h}(\mathrm{N}=107)$. The mean duration of mosquito control liquid vaporizers use was 8.96 $(\mathrm{SD} \pm 2.4) \mathrm{h}(\mathrm{N}=51)$. Ant repellents and mothballs were used 2-5 times on average in the past 6 months in 10 of 34 (29.4\%) and 12 of 25 (48\%) households, respectively. An ant repellent was used mostly in the living area of 17 of 34 households (50\%), while mothballs were used in the sleeping area of 15 out of 25 households (60\%). "Poison chalk" was used once in the past 6 months in 5 out 


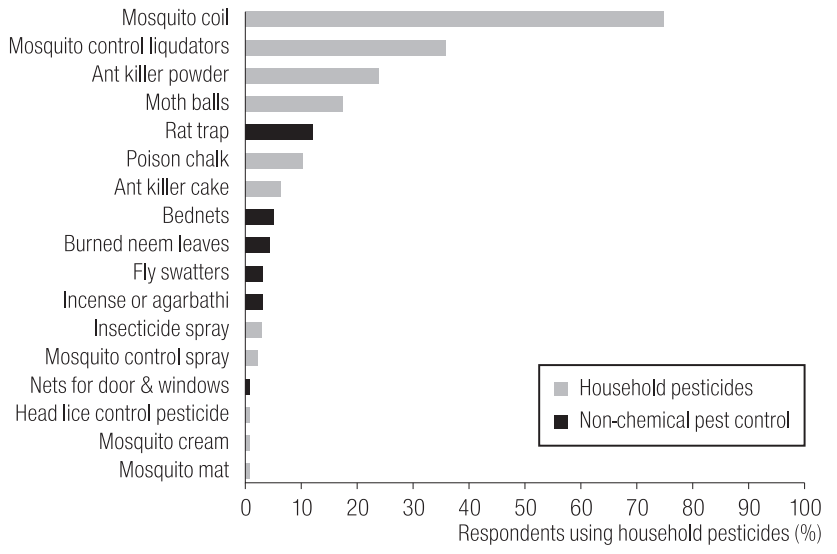

Fig. 1. Prevalence of different types of pest control methods ( $\mathrm{N}=143$ ), Nemam village, Tamil Nadu, India, 2010

of 15 households (33\%). It was used in the cooking area in $93.3 \%$ of the surveyed households $(\mathrm{N}=14)$ (Table 2).
Mosquito coils were usually brought loose everyday from the local shop without any packaging $(\mathrm{N}=82 ; 76.6 \%)$. The ant repellent was stored in the living area $(\mathrm{N}=14 ; 41.2 \%)$ or in the cooking area $(\mathrm{N}=8 ; 23.5 \%)$. "Poison chalk" was also stored in the living area $(\mathrm{N}=2 ; 53.3 \%)$ and cooking area $(\mathrm{N}=8 ; 53.3 \%)$. Mothballs were stored in the sleeping area $(\mathrm{N}=15 ; 60 \%)$. The moth balls were often $(\mathrm{N}=22 ; 88 \%)$ left in the place of use, where they gradually vaporized. With the exception of mothballs, the household pesticides products were disposed by being thrown away outside or into the dustbins (Table 2).

Among the mosquito coil users, $52 \%(\mathrm{~N}=56)$ reported not washing hands after touching the product and $61 \%$ $(\mathrm{N}=65)$ keeping the windows and doors closed while the coil was burning (Figure 2). Doors and windows were

Table 2. Practices regarding five commonly used household pesticides, Nemam village, Tamil Nadu, India, 2010

\begin{tabular}{lccccc}
\hline \multicolumn{1}{c}{ Parameters } & $\begin{array}{c}\text { Mosquito coil } \\
(\mathrm{N}=107) \\
\mathrm{n}(\%)\end{array}$ & $\begin{array}{c}\text { Mosquito control } \\
\text { liquid vaporizer } \\
(\mathrm{N}=51) \\
\mathrm{n}(\%)\end{array}$ & $\begin{array}{c}\text { Ant repellent } \\
(\mathrm{N}=34) \\
\mathrm{n}(\%)\end{array}$ & $\begin{array}{c}\text { Moth balls } \\
(\mathrm{N}=25) \\
\mathrm{n}(\%)\end{array}$ & $\begin{array}{c}\text { Poison chalk } \\
(\mathrm{N}=15) \\
\mathrm{n}(\%)\end{array}$ \\
\hline $\begin{array}{l}\text { Frequency of use } \\
\text { everyday }\end{array}$ & $63(58.9)$ & $39(76.5)$ & $2(5.9)$ & $2(8.0)$ & $1(6.7)$ \\
at least once per week & $26(24.3)$ & $8(15.7)$ & $9(26.5)$ & - & $2(13.3)$ \\
at least once a month & $12(11.2)$ & $2(3.9)$ & $11(32.4)$ & $4(16.0)$ & $5(33.3)$ \\
at least once in the past 6 months & $6(5.6)$ & $2(3.9)$ & $12(35.3)$ & $19(76.0)$ & $7(46.7)$ \\
Place of use & & & & & \\
bedroom/sleeping area & $72(67.3)$ & $38(74.5)$ & $14(41.2)$ & $15(60.0)$ & $7(46.7)$ \\
living room/living area & $43(41.3)$ & $21(41.2)$ & $17(50.0)$ & $3(12.0)$ & $7(46.7)$ \\
kitchen/cooking area & - & - & $12(35.3)$ & - & $14(93.3)$ \\
bathroom & - & - & $14(41.2)$ & $3(12.0)$ & - \\
Place of storage & & & & & \\
bedroom/sleeping area & $12(11.2)$ & $23(45.1)$ & $7(11.8)$ & $15(60.0)$ & $2(53.3)$ \\
living room/living area & $30(28.0)$ & $24(47.1)$ & $14(41.2)$ & $3(12.0)$ & $4(26.7)$ \\
kitchen/cooking area & $8(7.5)$ & $4(7.8)$ & $8(23.5)$ & - & $8(53.3)$ \\
not stored & $47(43.9)$ & - & - & - & - \\
Disposal method & & & & & - \\
throw it away & $49(46.2)$ & $14(27.5)$ & $14(41.2)$ & - & $2(13.3)$ \\
throw it into dustbins & $43(40.6)$ & $36(70.6)$ & $12(35.3)$ & $3(12.0)$ & $9(60.0)$ \\
other & $14(13.1)$ & $1(2.0)$ & $8(23.5)$ & $22(88.0)$ & $4(26.7)$ \\
\hline
\end{tabular}




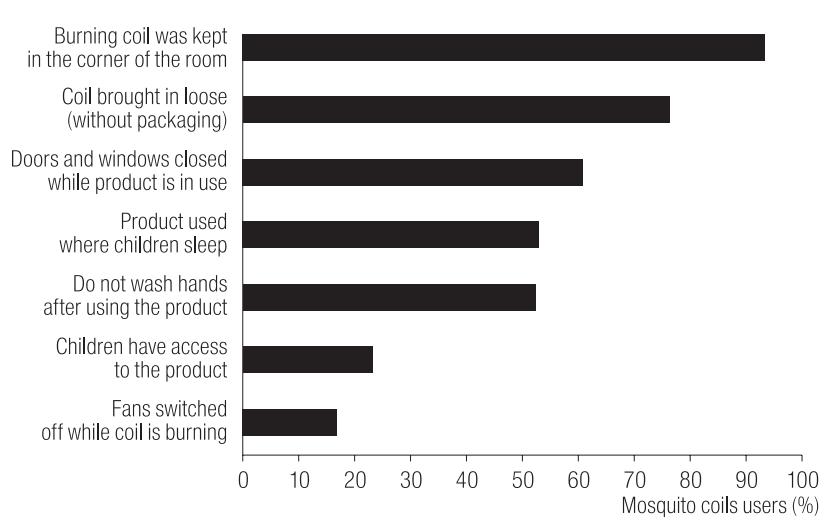

Fig. 2. Unsafe practices among the mosquito coil users ( $\mathrm{N}=107$ ) of Nemam village, Tamil Nadu, India, 2010

reported to be closed by $58.8 \%(\mathrm{~N}=30)$ of the users of mosquito liquid vaporizers. Food and drinks were reported not to be covered (while the product was used) by $19.6 \%$ $(\mathrm{N}=10)$ of the mosquito control liquid vaporizer users and by $20.6 \%(\mathrm{~N}=7)$ of the users of ant repellent.
Among the 95 households with children under 18 years of age, 35 households used mosquito liquid vaporizers, out of which $71.4 \%(\mathrm{~N}=25)$ reported their use in the children's sleeping area. Among the 143 respondents, 12\% $(\mathrm{N}=17)$ read the label of the household pesticide products and $11.2 \%(\mathrm{~N}=16)$ were aware of the presence of the toxicity symbols. Out of the 16 who were aware of the toxicity symbols, $62 \%$ did not know the significance and meaning of the symbols (data not shown in the tables).

Fifty percent of the users of mosquito coils, $43 \%$ of the mosquito liquid vaporizer users and $50 \%$ of the ant repellent users knew that these products were harmful to their own health and to the health of their children. Fifty six percent of the moth ball users and $67 \%$ of the "poison chalk" users did not perceive them as harmful to their own or their children's health. Among the users of various household pesticides, from $58 \%$ (mosquito coil

Table 3. Risk perception of the study participants, Nemam village, Tamil Nadu, India, 2010

\begin{tabular}{lccc}
\hline \multicolumn{1}{c}{ Risk perception } & $\begin{array}{c}\text { Agree } \\
\mathrm{n}(\%)\end{array}$ & $\begin{array}{c}\text { Disagree } \\
\mathrm{n}(\%)\end{array}$ & $\begin{array}{c}\text { Don't know } \\
\mathrm{n}(\%)\end{array}$ \\
\hline $\begin{array}{l}\text { Use of the product is harmful to my health } \\
\text { mosquito coil }(\mathrm{N}=107)\end{array}$ & $53(49.5)$ & $14(13.1)$ & $40(37.4)$ \\
mosquito control liquid vaporizer $(\mathrm{N}=51)$ & $22(43.1)$ & $7(13.7)$ & $22(43.1)$ \\
ant repellent $(\mathrm{N}=34)$ & $17(50.0)$ & $3(8.8)$ & $14(41.2)$ \\
moth balls $(\mathrm{N}=25)$ & $6(24.0)$ & $5(20.0)$ & $14(56.0)$ \\
poison chalk $(\mathrm{N}=15)$ & $5(33.3)$ & 0 & $10(66.7)$ \\
Use of the product is harmful to the health of children & & & \\
mosquito coil $(\mathrm{N}=107)$ & $53(49.5)$ & $12(11.2)$ & $42(39.3)$ \\
mosquito control liquid vaporizer $(\mathrm{N}=51)$ & $22(43.1)$ & $7(13.7)$ & $22(43.1)$ \\
ant repellent $(\mathrm{N}=34)$ & $17(50.0)$ & $3(8.8)$ & $14(41.2)$ \\
moth balls $(\mathrm{N}=25)$ & $7(28.0)$ & $4(16.0)$ & $14(56.0)$ \\
poison chalk $(\mathrm{N}=15)$ & $5(33.3)$ & 0 & $10(66.7)$ \\
Use of the product is harmful to the environment & & & \\
mosquito coil $(\mathrm{N}=107)$ & $32(29.9)$ & $13(12.1)$ & $62(57.9)$ \\
mosquito control liquid vaporizer $(\mathrm{N}=51)$ & $12(23.5)$ & $6(11.8)$ & $33(64.7)$ \\
ant repellent $(\mathrm{N}=34)$ & $10(29.4)$ & $4(11.8)$ & $20(58.8)$ \\
moth balls $(\mathrm{N}=25)$ & $3(12.0)$ & $4(16.0)$ & $18(72.0)$ \\
poison chalk $(\mathrm{N}=15)$ & $2(13.3)$ & 0 & $13(86.7)$ \\
\hline
\end{tabular}


users) to $87 \%$ ("poison chalk" users) did not know that the use of certain household pesticides could harm the environment (Table 3).

\section{DISCUSSION}

The prevalence of the use of household pesticides was found to be high in a rural village in Tamil Nadu, South India. Out of the pest control products, mosquito control products and particularly mosquito coils were widely used in the village. The use of non-chemical methods of pest control was low in the community. The majority of the inhabitants were using and handling household pesticides in an unsafe manner. Furthermore, most of them did not perceive household pesticides to be harmful to their own health or the health of their children.

Common use of insecticides (like mosquito coils, mosquito control liquid vaporizers, ant repellents) by our respondents suggests that insect pests are widespread in this rural area. When compared to urban Chennai and other parts of India, the prevalence of mosquito control products in the study area was comparatively higher (urban Chennai $-42 \%$ respondents used mosquito coils and $28 \%$ used mosquito liquids [17]; urban Pondicherry - 96\% used liquid vaporizers; rural Pondicherry - 44\% [13]; coastal Pondicherry - 50\% [14]). Three-fourths of the study participants used mosquito coils daily and made both the adults and the children exposed to the smoke that emanated from the mosquito coil. The smoke contains particulate matter consisting of formaldehyde and polyaromatic hydrocarbons [24] and could lead to respiratory diseases (asthma) and lung cancer [10,11].

The unsafe use of household pesticides increased the quantum of exposure for the study participants. The mosquito coil use in a well-ventilated room would decrease exposure [25]. However, $60 \%$ of the respondents reported closing the doors and windows while the mosquito coil was burning. Similarly, among the mothball users, the majority left them in the place of use, until they fully vaporized. The active ingredient of the moth balls is naphthalene, a probable carcinogen that turns volatile at room temperature [6]. Hence, this process could potentially increase ambient levels of naphthalene leading to long periods of exposure within the households. The manufacturer's instructions for the use of mosquito coils as well as moth balls did not reach the majority of our respondents, as they bought the coils or mothballs loose (without packaging) from the local shops.

Our respondents did not perceive the use of household pesticides to be a high potential health risk. This could be the reason for the low prevalence of non-chemical methods of pest control. The lower prevalence of the use of non-chemical methods has been corroborated by studies in other parts of the country. For instance, the major nonchemical methods of mosquito control include the use of bed nets (Gujarat - 39\% [16]; urban Chennai - 4.5\% [17]; urban Delhi slum - 2\% [26]) and burning leaves from Neem trees or other solid waste to generate smoke that can drive the mosquitoes away (Gujarat - 5\% [16]; Pondicherry - 2\% [14]; urban Chennai - 6.8\% [17]). The safe alternatives to the use of chemical repellents (Sharma [27] included source reduction for controlling mosquitoes, the use of mosquito nets (treated or untreated) and the use of neem oil (as skin creams or burning neem oil in kerosene)). However, use of such non-chemical methods is not always a healthy alternative. The burning of agricultural waste and neem leaves may lead to the release of high levels of particulate matter and other harmful combustion products [15]. Hence, any advocacy on the non-chemical methods needs to be based on a review of the benefits and risks involved.

Our study had limitations. Firstly, the study could suffer from problems of recall. There could be information bias in the form of underreporting the use of household pesticides, especially when the information is collected with reference to a recall period [3]. However, we used a recall 
period of 6 months (as in Bass et al., 2001) as compared to one year period used by others [3]. Hence, we anticipate that the problems related to recall may be minimal compared to other studies. Nonetheless, even if underreporting occurred, the high estimated prevalence of the use of household pesticides calls for immediate attention. Secondly, the external validity of the study may be limited since the selection of the study area was based on convenience. However, this does not prevent us from concluding that the information generated requires immediate public health action.

We conclude that the use of household pesticides was high in this rural community, along with unsafe practices. The level of the health risk perception regarding the use of the household pesticides was low. We recommended increasing the awareness in the community on the proper and safe use of chemical household pesticides coupled with safe and non-chemical methods of pest control. As a long-term measure, we suggest the regulation of the non-agricultural pesticide market, especially as regards the labeling and packaging methods and the responsibility at the point of sale. Finally, we recommend further research for in-depth information on the users' beliefs and risk perception concerning the household pesticide exposure, which is crucial to the development of effective and culturally appropriate health education materials.

\section{ACKNOWLEDGEMENTS}

We thank Dr. Sumathi Ramalingam for translating our questionnaire. We would like to thank the ICMR School of Public Health Study team which consisted of Dr. Amitabha Dan, Dr. Bibhash Roy, Dr. Debakanta Naik, Dr. Ganesha Hanumantharaju, Dr. Gudadappa Kasabi, Dr. Harishwara C. Eswara, Dr. Helen J. Uriah, Dr. Jayanta Maitra, Dr. Kunal Kanti De, Dr. Laxmi Devi, Dr. Mariappan Sakkanan, Dr. Parthiban Shanmugam, Dr. Prakash K. Shivarudrappa, Dr. Probin Chandra Arambam, Dr. Raghavendra K. Nagaiah, Dr. Ramesh Reddy
Allam, Dr. Ravi Kumar Ningaiah S., Dr. Somorendro Singh L., Dr. Stalin Jose J.S., Dr. Sumathi Ramalingam, Dr. Supriya Chaudhuri, Dr. Madasamy Suresh, Dr. Uma Shankar Shivalingappa for helping with the conduct of the study. We would also like to thank the field staff of the National Institute of Epidemiology for helping us with the field data collection.

\section{REFERENCES}

1. Grossman J. What's hiding under the sink: dangers of household pesticides. Environ Health Perspect 1995;103(6):550-4.

2. World Health Organization. Safe and effective use of household insecticide products. Geneva: World Health Organization; 1999.

3. Grey CNB, Nieuwenhuijsen MJ, Golding J. Use and storage of domestic pesticides in the UK. Sci Total Environ 2006;368(23):465-70.

4. Bass JK, Ortega L, Rosales C, Petersen NJ, Philen RM. What's being used at home: a household pesticide survey. Rev Panam Salud Publica 2001;9(3):138-44 [in Spanish].

5. Daniels JL, Olshan AF, Teschke K, Hertz-Picciotto I, Savitz DA, Blatt J, et al. Residential pesticide exposure and neuroblastoma. Epidemiology 2001;12(1):20-7.

6. Griego FY, Bogen KT, Price PS, Weed DL. Exposure, epidemiology and human cancer incidence of naphthalene. Regul Toxicol Pharmacol 2008;51(2 Suppl):S22-6.

7. Kato I, Watanabe-Meserve H, Koenig KL, Baptiste MS, Lillquist PP, Frizzera G, et al. Pesticide product use and risk of non-Hodgkin lymphoma in women. Environ Health Perspect 2004;112(13):1275-81.

8. Menegaux F, Baruchel A, Bertrand Y, Lescoeur B, Leverger G, Nelken B, et al. Household exposure to pesticides and risk of childhood acute leukaemia. Occup Environ Med 2006;63(2):131-4.

9. Teitelbaum SL, Gammon MD, Britton JA, Neugut AI, Levin B, Stellman SD. Reported Residential Pesticide Use and Breast Cancer Risk on Long Island, New York. Am J Epidemiol 2007;165(6):643-51. 
10. Fagbule D, Ekanem EE. Some environmental risk factors for childhood asthma: A case-control study. Ann Trop Paediatr 1994;14(1):15-9.

11. Shu-Chen C, Ruey-Hong W, Li-Jie S, Ming-Chih C, Huei L. Exposure to Mosquito Coil smoke may be a risk factor for lung cancer in Taiwan. J Epidemiol 2008;18(1):19-25.

12. IndiaPKwire. GoodKnight ADVANCED Activ + System becomes India's first product in household insecticide category to win "Product of the Year 2009 Award". Hyderabad: IndiaPKwire; 2009.

13. Snehalatha KS, Ramaiah KD, Vijay Kumar KN, Das PK. The mosquito problem and type and costs of personal protection measures used in rural and urban communities in Pondicherry region, South India. Acta Trop 2003;88(1):3-9.

14. Boratne AV, Datta SS, Singh Z, Purty AJ, Jayanthi V, Senthilvel V. Attitude and practices regarding mosquito borne diseases and socio-demographic determinants for use of personal protection methods among adults in coastal pondicherry. Indian J Med Spec 2010;1(2):91-6.

15. Babu BV, Mishra S, Swain BK. Personal-protection measures against mosquitoes: A study of practices and costs in a district, in the Indian state of Orissa, where malaria and lymphatic filariasis are co-endemic. Ann Trop Med Parasitol 2007;101(7):601-9.

16. Pandit N, Patel Y, Bhavsar B. Awareness and practice about preventive method against mosquito bite in Gujarat. Health Line 2010;1(1):16-20.

17. Vijay Kumar KN, Ramaiah KD. Usage of personal-protection measures against mosquitoes and the low prevalences of Wuchereria bancrofti microfilaraemia in the Indian city of Chennai. Ann Trop Med Parasitol 2008;102(5):391-7.
18. Arcury TA, Quandt SA, Russell GB. Pesticide safety among farmworkers: perceived risk and perceived control as factors reflecting environmental justice. Environ Health Perspect 2002;110 Suppl 2:233-40.

19. Palis FG, Flor RJ, Warburton H, Hossain M. Our farmers at risk: behaviour and belief system in pesticide safety. J Public Health (Oxf) 2006;28(1):43-8.

20. Census data online [cited 2010 Jun 7]. Available from URL: http://www.censusindia.net.

21. Government of India. Shri Sharad Pawar, Minister of Agriculture and Public Distribution. Pesticide management bill, 2008 [cited 2012 Mar 17]. Available from URL: http:// www.prsindia.org/uploads/media/1224668021/1224668021_ The_Pesticides_Management_Bill_2008.pdf.

22. Centres for Disease Control and Prevention. EpiInfo for Windows [computer program]. Version 3.5.2. Atlanta: CDC; 2010. 23. SPSS Inc. SPSS for Windows [computer program]. Version 16.0.2. Chicago: SPSS; 2008.

24. Liu W, Zhang J, Hashim JH, Jalaludin J, Hashim Z, Goldstein BD. Mosquito coil emissions and health implications. Environ Health Perspect 2003;111(12):1454-60.

25. Reckitt Benckiser Pty Ltd. Mosquito coil MSDS [product MSDS sheet] [cited 2009 Nov 9]. Australia: Reckitt Benckiser Pty; 2009. Available from URL: http://www.rbmsds.com.au/uploadedFiles/pdf/Mortein\%20Mosquito\%20 Coils-v7-31339.pdf.

26. Srinivas G, Edwin Amalraj R, Dhanraj B. The use of personal protection measures against malaria in an urban population. Public Health 2005;119(5):415-7.

27. Sharma VP. Health hazards of mosquito repellents and safe alternatives. Curr Sci 2001;80(3):341-3.

This work is available in Open Access model and licensed under a Creative Commons Attribution-NonCommercial 3.0 Poland License - http://creativecommons.org/ licenses/by-nc/3.0/pl/deed.en. 